Brandoria era d'etá d'anni ventiquattro, ed era tanto bella, che assai volte nella sua camera, sé medesima specchiandosi, maladiva chi mai l'aveva dato per marito Guido d'Antona ch'era vecchio canuto per modo che non si curava di donna. E diceva: "Il padre mio doveva bene pensare che'l duca Guido aveva passati tanti anni sanza moglie, perché poco amore di donna regnava in lui: o se da giovane non ebbe amore di donna, o come l'ará ora in vecchiezza? $\mathrm{E}$ io, misera, mi perdo il tempo mio, e sono pasciuta di baci e di promesse e di belli vestimenti, e vivo combattendo con l'amore e da lui riscaldata; e quando veggio il mio vecchio marito, non sono si allegra che io non mi contristi, e convienmi sforzare di celare il mio pensiero e ridere quando no voglia de piangere.

Las sub-tradiciones judeo-españolas de Salónica, Lárissa, Sofía y Estanbul conservan perfectamente esta escena de su antepasado épico. La correspondencia no puede ser más exacta. Citamos de la versión salonicense de Attias (núm. 50.9-28):

El día de la su boda, bien oiréis lo que ḥué a pensar; tomó peine d'oro en mano, sus cabellos hụué a peinar; en la su mano derecha tiene un espejo cristal, mirando se va su puerpo y el su lindo asemejar. Bendiciendo va del vino, bendiciendo va del pan, bendiciendo al Dió del cielo, que tan linda la hue a criar; maldiciendo padre y madre, que un viejo le hué a dar.

La casaron con un viejo, viejo es, d'alta idad. La niña quiere juguetes, el viejo quiere holgar. Lloraba la blanca niña, lágrimas de veluntad...

La presencia de una escena esencialmente idéntica en el romance Casada con un viejo (é) habrá motivado la contaminación, en grado mayor o menor, de muchas versiones orientales de Celinos con este poema independiente aunque de tema afín. Véase por ejemplo el núm. $10 A$ de Diez romances, donde el poema en -é absorbe casi todo el texto. Para el motivo del espejo en el congénere francés de Casada con un viejo, véase Chapbooks, p. 233.

\title{
EL RUCIO DE SANCHO Y LA FECHA DE COMPOSICIÓN DE LA SEGUNDA PARTE DE DON QUIJOTE*
}

Es bien sabido que entre la primera y segunda edición de la primera parte del Quijote que en 1605 hizo Juan de la Cuesta hay sustanciales diferencias textuales; las más importantes de ellas tratan sobre el robo y recuperación del burro de Sancho. En la primera edición, que apareció en enero de $1605^{1}$, encontramos de repente en el

* Quiero agradecer al profesor Alan S. Trueblood por la lectura de este artículo y sus profundos y útiles comentarios sobre el mismo.

1 La tasa de la primera parte está fechada el 20 de diciembre de 1604; el libro no tiene colofón, pero las preliminares de la segunda edición, hecha en Lisboa, están fechadas el 26 de febrero y el $1^{\circ}$ de marzo de 1605 . Si no fue publicada en enero debe haber aparecido en los primeros días de febrero. 
capítulo 25, después que se alude a la presencia del rucio, que Sancho se queja por el robo de que fue objeto, sin que haya discusión o referencia a éste. Veinte capítulos más adelante leemos que, inexplicablemente, el burro está presente, sin que se nos haya facilitado explicación alguna sobre su recuperación. En la segunda edición de Juan de la Cuesta (cuarta del Quijote), que apareció hacia junio de $1605^{2}$, hallamos dos pasajes adicionales: el primero -en el capítulo 23- describe el robo del asno; el segundo -capítulo 30- habla de su recuperación. En este trabajo intento explicar lo que implican estas diferencias entre las dos ediciones.

Nadie que estudie el Quijote puede dejar de darse cuenta de las contradicciones de la primera edición, porque, para nuestra sorpresa, se discuten en la novela misma. En II, 3, don Quijote dice a Sansón Carrasco, "El [libro] que de mí trata... a pocos habrá contentado", y Sansón le responde: "antes es al revés; que como de stultorum infinitus est numerus, infinitos son los que han gustado de la tal historia; y algunos han puesto falta y dolo en la memoria del autor, pues se le olvida de contar quién fue el ladrón que hurtó el rucio a Sancho, que allí no se declara, y sólo se infiere de lo escrito que se le hurtaron, y de allí a poco le vemos a caballo sobre el mesmo jumento, sin haber parecido" "3. Quiero insistir en que el comentario de Sansón es válido sólo con respecto a la primera edición.

Tenemos que contestar a dos preguntas: ¿a qué se deben las incongruencias de la primera edición, y de qué manos son las correcciones de la segunda edición de Juan de la Cuesta? En cuanto a aquélla, todavía encontramos la sugerencia de que los defectos de la primera edición se explican por algún error del impresor. Esta explicación también se encuentra en el Quijote, en II, 27, al principio de la aventura del rebuzno, donde se dice: "Este Ginés de Pasamonte, a quien don Quijote llamaba Ginesillo de Parapilla, fue el que hurtó a Sancho Panza el rucio; que por no haberse puesto el cómo ni el cuándo en la primera parte, por culpa de los impresores, ha dado en qué entender a muchos, que atribuian a poca memoria del autor la falta de emprenta".

Creo que esta explicación es totalmente inaceptable. No dudo ni por un instante de que un impresor sea capaz de caer en tamaño error. Pero los errores de los impresores son de la clase que puede explicarse fácilmente como descuido - una línea que se salta, a veces una página que se omite. Ningún impresor eliminaría accidentalmente dos pasajes diferentes en dos capítulos tan separados uno del otro, y que tratan el mismo tema. Si, en efecto, el culpable de la omisión fuera el impresor, nada más sencillo para poner remedio al asunto que corregir el

2 Porque la quinta edición -que por cotejo puede deducirse que fue basada en la cuarta- tiene una aprobación fechada en julio de 1605. Véase Leoponno Rus, Bibliografia critica de las obras de Miguel de Cervantes Saavedra, t. 1, 1895, pp. 8-10 (reimpr. New York, 1970) .

3 Las citas del Quijote corresponden a la "nueva edición crítica" de Rodríguez Marín, Madrid, 1947.49; respeto su ortografía y puntuación. A pesar de ello, en todos los casos he controlado los pasajes con los facsímiles de las ediciones originales. 
error en la siguiente edición; pero la segunda de Juan de la Cuesta no devuelve las cosas a la normalidad de manera correcta, porque si es cierto que se habla del robo del asno en el cap. 23, Sancho sigue montando su rucio en el mismo capítulo y en el cap. 25. En pocas palabras, de ninguna manera un error accidental del cajista puede explicar las incongruencias de la primera edición de Juan de la Cuesta ${ }^{4}$.

Debe advertirse, además, que fue Cide Hamete quien sugirió que la culpa era del impresor, y que los errores que trata de explicar son, en el contexto de la novela, sus propios errores. Deberíamos recordar también que, según don Quijote (II, 3), "de los moros no se podía esperar verdad alguna, porque todos son embelecadores, falsarios y quimeristas", y según Cervantes, "[es] muy propio de los [arábigos] ser mentirosos" (I, 9). Como para acentuar lo poco confiable que es Cide Hamete, sólo pocas líneas antes de sugerir que las faltas son de los impresores, el capítulo se abre con la siguiente introducción: "Entra Cide Hamete, coronista desta grande historia, con estas palabras en este capítulo: "Juro como católico cristiano...", a lo que su traductor dice que el jurar Cide Hamete como católico cristiano siendo él moro, como sin duda lo era, no quiso decir otra cosa sino que así como el católico cristiano cuando jura, jura o debe jurar verdad y decirla en lo que dijere, así él la decía, como si jurara como cristiano católico, en lo que quería escribir de don Quijote..." (II, 27).

En un excelente trabajo ${ }^{5}$, Geoffrey Stagg ha dado una explicación más satisfactoria de las incongruencias de la primera edición. De su examen del texto, concluye que el episodio de Grisóstomo y Marcela se hallaba originalmente en una sección más avanzada de la primera parte, y fue cambiada a donde ahora se halla, en los caps. 11-14; el cambio provocó, entre otras cosas, una equivocación en el epígrafe del capítulo $10^{6}$. Sugiere Stagg que el robo del asno era originalmente parte del episodio pastoril, y fue suprimido cuando éste cambió de lugar.

Por consiguiente, Cervantes no se dio cuenta de las contradicciones resultantes hasta que se las mostraron después de la publicación de la primera edición; como señala Sansón Carrasco en la conversación en

4 Las pruebas que presenta el texto también apoyan la opinión de que las incongruencias pertenecen más a Cervantes que a los impresores. En II, 4, Sancho explica a Sansón Carrasco que el robo del burro ocurrió mientras él dormía, claro intento de justificar el no haberse mencionado el robo en la primera parte. EI primer pasaje interpolado nos recuerda quién era Ginés de Pasamonte, algo que no esperaríamos si ese trozo se hubiera omitido accidentalmente en la primera edición, ya que la aventura de los galeotes había ocurrido en el capítulo anterior; véase Don Quijote de la Mancha, I, ed. Schevill y Bonilla, Madrid, 1928, p. 495. Por último, Ia palabra "rucio" se usa primero en este pasaje interpolado (véase Don Quijote de la Mancha, ed. D. Clemencín, [ $2^{2}$ ed.?], Madrid, 1966, I, 23 nota 16); la palabra se usa sobre todo en la segunda parte. (Mi agradecimiento a A. D. Kossoff por señalarme este hecho, y a E. Ruiz Fornells por facilitarme la página con la palabra "rucio" de las concordancias del Quijote que él prepara).

5 "Revision in Don Quixote, Part I", en Hispanic studies in honour of $I$. González Llubera, Oxford, 1959 , pp. 347-366.

6 El título del cap. 10 anuncia la aventura de los yangüeses, que tiene lugar en el cap. 15. Encuentro la explicación de Stagg más convincente que las teorías de P. Ullanan (véase su artículo "The heading of chapter $\mathrm{X}$ in the 1605 Quijote", FMLS, 7, 1971, 43-51). 
que se mencionan por primera vez los descuidos relativos al asno: “... como las obras impresas se miran despacio, fácilmente se veen sus faltas... quisiera yo que los tales censuradores fueran más misericordiosos y menos escrupulosos, sin atenerse a los átomos del sol clarísimo de la obra de que murmuran; que... aliquando bonus dormitat Homerus" (II, 3). En consecuencia debemos concluir que los pasajes interpolados, si no fueron omitidos en la primera edición, fueron escritos después de la aparición de ésta, en 1605, para que se incluyeran en la segunda edición de Juan de la Cuesta.

Tenemos ahora que decidir la autoría de esos pasajes, problema que sólo podemos resolver examinando el texto, nuestra única prueba. El primer pasaje, el más extenso, dice, en parte, así:

Dormía Sancho Panza, hurtóle su jumento, y antes que amaneciese se halló bien lejos de poder ser hallado. Salió el aurora alegrando la tierra y entristeciendo a Sancho Panza, porque halló menos su rucio; el cual, viéndose sin él, comenzó a hacer el más triste y doloroso llanto del mundo; y fue de manera, que don Quijote despertó a las voces, y oyó que en ellas decía: " $\mathrm{OOh}$ hijo mío de mis entrañas, nacido en mi mesma casa, brinco de mis hijos, regalo de mi mujer, envidia de mis vecinos, alivio de mis cargas, y, finalmente, sustentador de la mitad de mi persona..." (I, 23).

Según Riquer, "las líneas... son del inconfundible estilo de Cervantes" 7; es punto menos que imposible que el trozo haya sido escrito por alguien que no fuera él. Incluso si alguien pudiera haber imitado la exagerada preocupación de Sancho $^{8}$-poco probable si se tratara sólo de corregir sin alardes la falta del autor- el estilo del trozo, con una sucesión de frases breves y rápidas, y su oposición "alegrando la tierra y entristeciendo a Sancho", es, sin que quepa error, el estilo cervantino, y hubiera sido casi imposible imitarlo en aquel tiempo ${ }^{9}$ Avellaneda imitó los temas, pero no el lenguaje de Cervantes, y mientras el estudio del estilo como retórica estaba en esa época muy desarrollado, el concepto del estilo inconfundible de un autor apenas existía ${ }^{10}$.

Lo que hasta ahora he expuesto no es nuevo. Aunque no es una postura universalmente aceptada, muchos eruditos consideran que estos pasajes son de Cervantes. Llegamos ahora al punto básico: tenemos que enfrentarnos con el hecho de que las inconsecuencias que atañen al asno de Sancho se discuten bastante en la segunda parte, cuando ya estaban corregidas en 1605 en la segunda edición de Juan de la Cuesta, y en todas las ediciones posteriores. ¿Por qué Cervantes pondría en boca de sus personajes ese llamado de atención a un error que se

7 Don Quijote de la Mancha, ed. M. de Riquer, 6a ed., Barcelona, 1969, I, p. 216, nota 3.

8 Cf. el llanto de Sancho, I, 52.

9 Véase en especial, Helmut Hatzfeld, El "Quijote" como obra de arte del lenguaje, trad. de M. Cardona, 2* ed., Madrid, 1966, pp. 212-225.

10 O, más exactamente, existía sólo en un sentido negativo, como la incapacidad de un autor (Góngora, Feliciano de Silva) de escribir en acuerdo con normas aceptadas; no existia el concepto moderno de que un autor tendrá, aun involuntariamente, un estilo particular. 
había corregido casi diez años atrás? No puede haber ignorado las revisiones de todas esas ediciones. Riquer supone que las correcciones no fueron de Cervantes y que las rechazó ${ }^{11}$, conclusión ésta que me parece poco atinada, puesto que nos llevaría a suponer que Cervantes escribió estos pasajes interpolados (conclusión que también comparte Riquer) pero, luego de escribirlos, los rechazó, y no hizo nada para cambiar las siguientes ediciones que quedaron sin corregir ${ }^{12}$. Hay una solución más sencilla y elegante: los pasajes de la segunda parte del Quijote donde se trata el tema fueron, en realidad, escritos en 1605, después de la publicación de la primera parte, pero antes de que se hicieran las correcciones en la segunda edición de Juan de la Cuesta.

Esta conclusión, quizá sorprendente, no está en desacuerdo con la algo confusa cronología cervantina ${ }^{13}$, ni está en conflicto con el tiempo ficcional de los primeros capítulos de la segunda parte. En ellos, don Quijote se sorprende ante el hecho de que la historia de sus aventuras esté ya impresa (II, 3), "pues aún no estaba enjuta en la cuchilla de su espada la sangre de los enemigos que había muerto" en la primera parte. Según Sansón Carrasco, "andaba ya en libros la historia de vuestra merced" (II, 2). Por último, don Quijote había guardado cama durante un mes desde que, enjaulado, regresó a su pueblo al final de la primera parte (II, 1); por febrero, un mes después de la publicación de la primera edición de Juan de la Cuesta, apareció la primera de las ediciones no autorizadas a las que se alude en II, $3^{14}$.

Supongo, pues, que algunos capítulos de la segunda parte del Quijote se escribieron en 1605 , poco después de la aparición de la primera ${ }^{15}$. Es obvio, sin embargo, que no toda la segunda parte fue escrita

11 Quijote, ed. de Riquer, I, p. 215, nota 3.

12 Generalmente se olvida que en la tercera edición de Juan de la Cuesta, la de 1608, el texto cambia más aún en otro intento poco feliz de dar coherencia a todas las referencias al burro. No está claro quién hizo esas correcciones.-Clemente Cortejón no menciona el problema del asno en su libro iCorrigió Cervantes alguna de las ediciones de "Don Quijote" impresas por Juan de la Cuesta? Barcelona, 1907.

13 El estudio más reciente sobre el tema es de RuTH EL Saffar, Novel to romance. A study of Cervantes's "Novelas ejemplares", Baltimore, 1974, p. 1, notas 1 y 2 y pp. 169-177. (Véase mi reseña de este libro en $N R F H, 23,1974,419-420$ ). Las referencias a las ediciones de la primera parte en el tercer capítulo de la segunda han complicado el problema de la fecha de ésta (véase la nota siguiente). I. SANCHEz, "A note on the date of composition of Don Quijote", HR, 4 (1936), 375-378, sugiere sólo que el cap. 17 de la segunda parte debe haber sido escrito en alguna fecha anterior a 1613. M. Buchanan ("The works of Cervantes and their dates of composition" en Transactions of The Royal Society of Canada, Series 3, 32, Section 2, May, 1938, pp. 34-35) cree que una alusión en II, I a un ataque de los turcos se refiere al de 1611-1612; según Riquer y Rodriguez Marín tales discusiones eran lugar común.

14 He señalado la indole irónica de esta discusión de la popularidad del Quijote en " Dígalo Portugal, Barcelona y Valencia»: una nota sobre la popularidad de Don Quijote", Hf, 1974, núm. 52, 71-72. Debo advertir también que el Guzmán de Alfarache, tan popular, fue impreso en esas ciudades; acaso en el pasaje se aluda a la obra de Alemán.

15 Sin embargo, es evidente que un intervalo más largo separó a la segunda parte de la escritura de la primera, que, según sabemos por los preliminares, estaría acabada hacia mediados de 1604. 
en ese año, puesto que contiene numerosas referencias al Quijote de Avellaneda, publicado en 1614, y a la expulsión de los moriscos, que aconteció en 1609-1610. En algún momento, pues, Cervantes dejó de escribir la segunda parte para retomarla años más tarde ${ }^{16}$. Ese momento debe ser posterior a los caps. 3 y 4, donde las equivocaciones se señalan por primera vez y en donde Sancho describe cómo, puesto que estaba dormido cuando ocurrió el robo, éste pasó desapercibido en la primera parte. También debe de ser posterior al cap. 27 -en donde Cide Hamete aclara que él no tuvo la culpa de los errores de la primera parte - y anterior al cap. 59, en el que por primera vez se nombra el Quijote de Avellaneda; en realidad debe ser anterior al cap. 36, en el cual Sancho termina la carta a su mujer "a veinte de julio 1614", fecha que por lo general, y creo que correctamente, se toma como aquélla en la que Cervantes estaba escribiendo el capítulo.

Después del capítulo 27 y antes del 36; resulta que entre ambos hay un corte natural. Aquí encontramos (cap. 29) la aventura del barco encantado, que no encaja bien con los capítulos que lo rodean ${ }^{17}$. Más significativo aún, en este momento de la segunda parte encontramos un gran salto geográfico; según José Terrero, Cervantes escribió allí "una de las páginas más antigeográficas de su gloriosa novela" $1 \mathrm{~s}$. Don Quijote y Sancho estaban en Castilla la Nueva, visitando la cueva de Montesinos; fueron luego al pueblo de los rebuznadores, que queda a pocas leguas ${ }^{19}$. Después de un viaje de sólo dos días, los encontramos a las riberas del Ebro, a unos quinientos kilómetros del lugar de partida. Esta discrepancia súbita y sin explicaciones sugiere que en este punto -entre el cap. 28, la aventura del rebuzno y el 29 , la aventura del barco encantado- Cervantes dejó de escribir la segunda parte, para retomarla años después. Con el cap. 30 comenzamos la visita a los Duques, el episodio más extenso de la segunda parte ${ }^{20}$.

16 Como aparentemente hizo con la primera parte del Quijote y quizá con el Persiles (véase R. Osuna, "Las fechas del Persiles", BICC, 25, 1970, 383-433). Su intención de continuar la Galatea está ampliamente documentada en los prólogos y en el escrutinio de la librería.

17 Observa R. PReDmore (El mundo del "Quijote", Madrid, 1958, p. 43) que "sólo una de las aventuras de la segunda parte se basa en deformación grosera de la realidad visible: el barco encantado". Me he preguntado, como otros también, si esta aventura fue escrita originalmente para ser incluida en la primera parte, acaso entre los caps. 20 y 21 , y si el río por el que viajaban no era originalmente el Ebro sino el Guadiana. Viajan sobre la orilla derecha del Ebro, río abajo, como en el caso del Guadiana (véase el principio de 1,21 ); la relación de Sancho con Don Quijote se parece a la de la primera parte (cf. los dos discursos que comienzan "has de saber...", en I, 20 y II, 29); y la confusión acerca de la palabra "longincuos" recuerda las "prevaricaciones idiomáticas" de Sancho, que son muy evidentes en este momento de la primera parte (véase STAGg, art. cit., p. 356).

18 "Itinerario del Quijote de Avellaneda y su influencia en el cervantino", $A C e r v$, 2 (1952), 183. Sobre pruebas textuales de este tipo en la segunda parte véase ahora L. A. Murillo, "The summer of myth: Don Quijote de la Mancha and Amadis de Gaula", PhQ, 51 (1972), 145-157.

19 Terrero, art. cit., p. 184.

20 Otra prueba textual apoya esta división, y es evidente que hace falta un estudio más profundo de la unidad de la segunda parte desde este punto de vista. En este momento de la segunda parte desaparecen los arcaísmos, típicos de la primera parte (véase JoHN J. ALLEN, Don Quixote: Hero or fool? A study in narrative 
La hipótesis de que los primeros 28 capítulos de la segunda parte fueron escritos en 1605, tiene algunas implicaciones importantes; bajo ningún punto de vista se eliminan las diferencias entre la primera y segunda parte de la novela, pero disminuye algo la importancia de esas diferencias y da un nuevo apoyo a los actuales cervantistas que ven sus obras "realistas" (el Quijote y las novelas ejemplares más conocidas) como trabajos tempranos, menos importantes para el mismo Cervantes que las obras más pulidas y más conscientemente literarias escritas hacia el final de su vida: el Persiles, las novelas ejemplares más idealistas y probablemente las perdidas Semanas del jardin ${ }^{\mathbf{2 1}}$.

Quisiera, sin embargo, desarrollar sólo una de las consecuencias de la fecha que propongo para la segunda parte del Quijote: su relación con el Quijote de Avellaneda, publicado en 1614. Una vieja sugerencia, que apoya ahora la fecha que propongo, es que, si Cervantes reanudó la escritura del Quijote poco antes del 20 de julio de 1614 -fecha en que Sancho escribe la carta a su mujer (II, 36) -, lo hizo a causa de la continuación de Avellaneda, como Mateo Alemán contestó con su propia continuación a la espuria segunda parte del Guzmán de Alfarache de Mateo Luján ${ }^{22}$. Cada detalle de la publicación del libro de Avellaneda ha sido objeto de grandes controversias, y no podemos decir, sin conocer ni al autor ${ }^{23}$, ni el lugar de publicación, que Cervantes había visto el libro de Avellaneda hacia julio de 1614; advierto, sin embargo, que las aprobaciones del Quijote de Avellaneda son del 18 de abril y del 4 de julio de 1614 , de modo que la obra estaba acabada para esa fecha ${ }^{24}$.

technique, Univ. of Florida Press, 1969, p. 57; he contestado a algunos argumentos de Alien en "Cervantes' Don Quijote once again: An answer to J. J. Allen", Studies in honor of Helmut Hatzfeld's 80th year, Barcelona, 1974, pp. 103-110). En el estudio de Hatzfeld, "Medios de enlace compositivo", op. cit., pp. 111-130, hay más ejemplos de la unión entre la primera parte y los primeros 28 capítulos de la segunda, que entre éstos y el resto de la segunda parte.

21 El Saffar, una vez más, es quien más recientemente ha escrito sobre este punto; véase su libro ya citado para la bibliografía sobre el tema.

22 Véase el prólogo al lector de la segunda parte de Mateo Alemán. Podría objetarse que la afirmación del prólogo a las Novelas ejemplares - "primero verás, y con brevedad, dilatadas las hazañas de Don Quijote y donaires de Sancho Panza"sugiere que Cervantes estaba trabajando en la segunda parte del Quijote en julio de 1613. Quizás; pero si así fuera, Cervantes escribió los primeros 36 capítulos al descansado ritmo de uno cada dos semanas (aceptando el 20 de julio de 1614 como fecha de composición del cap. 36; nótese que en el cap. 47 la carta del Duque a Sancho está fechada el 16 de agosto), lo cual contrasta con su comentario que el Conde de Lemos lo vería "con brevedad". En el Viaje del Parnaso, que no puede ser posterior a la primera mitad de 1614, Cervantes dice que el Persiles estaba "puesto a pique para dar a la estampa" (cap. 4), cuando en realidad no estuvo listo hasta su muerte. Sus repetidas alusiones a las Semanas del jardin sugieren también que Cervantes exageraba en algo el progreso de sus proyectos literarios. Cuando una obra estaba en verdad terminada, como la segunda parte del Quijote, tenía "calçadas las espuelas... para yr a besar los pies a V. E." (dedicatoria a Ocho comedias $y$ ocho entremeses).

23 Contra lo que cree S. GiLman, considero importante el problema de la identidad de Avellaneda (véase Cervantes y Avellaneda. Estudio de una imitación, México, 1951, p. 14).

24 A. LóPez Pel.ÁEz ("Aprobación verdadera del Quijote falso", BRAH, 68, 1916, 557-563) defiende las aprobaciones como correctas, pero L. Astrana Marín, sin 
Es evidente que Avellaneda imitó, tal como él los entendia, temas y aventuras de la primera parte de Cervantes. Sin embargo, las relaciones entre la continuación de Avellaneda y la segunda parte auténtica han constituido un problema sin solución desde que Diego Clemencín (ed. cit., II, 59, nota 56) señaló las sorprendentes coincidencias que hay entre los dos textos. Mientras don Quijote de Cervantes (II, 26) interrumpe la presentación del retablo de Maese Pedro, el de Avellaneda (II, 27) interrumpe la de El testimonio vengado de Lope, retando a los actores tal como el personaje cervantino había retado a las marionetas. El paralelismo es tan marcado que los dos episodios no pueden haber sido creados independientemente; más bien uno debe estar basado en el otro. Si estos capítulos de la segunda parte cervantina se escribieron en 1605, Avellaneda copió a Cervantes, no al revés, y debe haber conocido la segunda parte auténtica cuando estaba aún inédita, acaso de una lectura entre amigos. Esto coincide con lo que sabemos acerca de la divulgación de la obra de Cervantes, ya que el Persiles y posiblemente la primera parte del Quijote se conocieron en manuscrito antes de su publicación ${ }^{25}$.

Hay, sin embargo, otros paralelismos entre las dos segundas partes que no pueden explicarse de la misma manera. En Avellaneda (II, 35) Sancho escribe una carta a su mujer tal como lo hace el Sancho de Cervantes (II, 36) ; una vez más, estas cartas no parecen ser coincidentes sino relacionadas. Si la carta que Cervantes hace escribir a Sancho está fechada el 20 de julio de 1614, y la obra de Avellaneda fue terminada varios meses antes, Cervantes tenía algún conocimiento de ella antes de su publicación, tal como sugiere la forma similar en que don Quijote es tratado por los Duques en Cervantes y por el Archipámpano en Avellaneda ${ }^{26}$. Si ambos conocían sus respectivos trabajos, apoyaría este hecho la teoría de que Cervantes conocía a Avellaneda 27, como

aludir a este artículo, supone que las aprobaciones eran fraudulentas porque "ni aquellos eclesiásticos ni Felipe Roberto... podían autorizar con sus nombres una edición a espaldas de la Ley" (Vida ejemplar y heroica de Miguel de Cervantes Saavedra, t. 7, Madrid, 1958, pp. 166-167). No he podido consultar J. SERra VILARó, El "Quixot" d'Avellaneda fou imprès a Tarragona, Tarragona, 1936.

25 Véase el comentario sobre el Persiles en la dedicatoria a la segunda parte del Quijote. La lectura oral se ha sugerido como medio por el cual pudo haberse conocido la primera parte del Quijote en 1604. Sobre esta discusión representan los dos polos J. Oliver Asín, El "Quijote" de 1604, Madrid, 1948, y Astrana Marín, op. cit.s t. 6, pp. 104-106 y $A B C, 23$ de abril de 1949; véase también R. RicARD, "Emil Charles et le Quijote de 1604", $L R, 16$ (1962), 72.74.

26 Según R. Menéndez PIDAL, "puede sospecharse que el Quijote de Avellaneda circulaba en manuscrito, como tantas obras entonces, y que Cervantes tuvo de él conocimiento..." ("Un aspecto en la elaboración del Quijote", De Cervantes y Lope de Vega, 6a ed., Madrid, 1964, p. 60, nota 6). "Esto parece muy posible", confirma Gilman, op. cit., p. 170.-Para el tratamiento de otras similitudes entre las obras de Cervantes y Avellaneda véase GILMaN, op. cit., pp. 167-176; M. DE Rıquer en la introducción a su edición del Quijote de Avellaneda, Madrid, 1972, Clás. cast., núms. 174-176, pp. xxxv-xxxix; E. C. RILEY, Teoria de la novela en Cervantes, trad. de C. Sahagún, Madrid, 1966, pp. 338-340; véase también A. A. SICroff, "La segunda muerte de don Quijote como respuesta de Cervantes a Avellaneda", NRFH, 24 (1975), pp. 267-291.

27 A pesar del hecho de que Cervantes no podía identificarlo a través de su 
lo sugieren también la evidente enemistad personal, y la queja de Avellaneda de que Cervantes lo había ofendido en la primera parte del Quijote ${ }^{28}$.

Las sugerencias que hago aquí con respecto a Avellaneda son tentativas, algo inevitable, creo, en el caso de una obra sobre la que se conoce tan poco con certeza. Pero la composición en 1605 de un tercio de la segunda parte de Cervantes es la única forma de interpretar coherentemente los comentarios sobre la primera que nos da el texto.

Daniel Eisenberg

Florida State University.

\section{LOS DOS COMIENZOS DE LA HISTORIA DE CARDENIO}

El largo episodio (o novela) de los amores de Cardenio y de Dorotea ha merecido un interés erudito (en relación, especialmente, con su adaptación en el teatro isabelino) o temático, dentro de estudios globales del Quijote ${ }^{1}$. La personalidad misma de Cardenio ha llamado la atención como característica de un temperamento morboso ${ }^{2} \mathrm{y}$, recientemente, Gilman ha tratado sobre la función de su historia en relación con la idea cervantina de la comedia como equivalente de la novela de caballería ${ }^{3}$.

libro; véase A. SÁnchez, “¿Consiguió Cervantes identificar al falso Avellaneda?", ACerv, 2 (1952), 311-333.

28 "Tomó por tales [medios] el ofender a mi", ed. de Riquer, I, p. 9 . El estudio más actual y convincente de esta ofensa de la primera parte es el de Riquer, "El Quijote y los libros", PSA, 54 (1969), 5-24.-Ya escrito este trabajo, he visto la nota de Nicolás Marín, "Lope y el prólogo del Quijote apócrifo", Ins., 1974, mím. 336, en la cual propone que fue Lope, y no Avellaneda, el autor del prólogo a la espuria segunda parte. La tesis es interesante y la diferencia de estilo entre el prólogo y la obra de Avellaneda es evidente; sin embargo, no me convence la teoría de Marín de que Avellaneda intentó emular sinceramente a Cervantes, y quedan entonces sin explicación los "sinónimos voluntarios" de Cervantes que tanto ofendieron al autor del prólogo de la novela de Avellaneda.-No he podido ver todavía otro trabajo de Marín, "La piedra y la mano en el prólogo del Quijote apócrifo", en Homenaje a Guillermo Gustavino, Madrid, 1974, pp. 253-288.

1 Para la historia de las fuentes y las imitaciones de la novela de Cardenio, véase Raymond L. Grismer, Cervantes: A bibliography, New York 1946, t. 1, índices, y Dámaso Alonso, "Lope, Pedro de Cárdenas y los Cardemios", $R F E, 40$ (1956), 67-90. Entre los estudios temáticos más recientes se destaca el de ArTHur Erron, Don Quixote and the dulcineated world, University of Texas Press, 1971, pp. 125 ss., en cuanto a la estilización de la vida como constante del Quijote. Algunos críticos han tratado más o menos directamente la cuestión de la importancia de la historia de Cardenio en relación con la de don Quijote; véase especialmente E. C. RILEY. "Episodio novela y aventura en Don Quijote", ACerv, 5 (1955-56), 209-230, con la bibliografía pertinente.

2 Véase Alan S. Trueblood, "El silencio en el Quijote", NRFH, 12 (1958), es. pecialmente p. 632.

3 La conclusión del crítico es que la historia de Cardenio representa "la imposibilidad de cumplir con un papel literario -en este caso, social-literario [pues] 